\title{
Novel Neuronal Phenotypes from Neural Progenitor Cells
}

\author{
Eleni A. Markakis, ${ }^{1}$ Theo D. Palmer, ${ }^{2}$ Lynne Randolph-Moore, ${ }^{3}$ Pasko Rakic, ${ }^{1}$ and Fred H. Gage ${ }^{3}$ \\ ${ }^{1}$ Department of Neurobiology, Yale University School of Medicine, New Haven, Connecticut 06510, ${ }^{2}$ Department of Neurosurgery, Stanford University \\ Medical Center, Stanford, California 94305, and ${ }^{3}$ The Salk Institute for Biological Studies, Laboratory of Genetics, La Jolla, California 92037
}

We report the first isolation of progenitor cells from the hypothalamus, a derivative of the embryonic basal plate that does not exhibit neurogenesis postnatally. Neurons derived from hypothalamic progenitor cells were compared with those derived from progenitor cultures of hippocampus, an embryonic alar plate derivative that continues to support neurogenesis in vivo into adulthood. Aside from their different embryonic origins and their different neurogenic potential in vivo, these brain regions were chosen because they are populated with cells of three different categories: Category I cells are generated in both hippocampus and hypothalamus, Category II cells are generated in the hypothalamus but are absent from the hippocampus, and Category III is a cell type generated in the olfactory placode that migrates into the hypothalamus during development. Stem-like cells isolated from other brain regions, with the ability to generate neurons and glia, produce neurons of several phenotypes including gabaergic, dopaminergic, and cholinergic lineages. In the present study, we extended our observations into neuroendocrine phenotypes. The cultured neural precursors from 7-week-old rat hypothalamus readily generated neuropeptide-expressing neurons. Hippocampal and hypothalamic progenitor cultures converged to indistinguishable populations and produced neurons of all three categories, confirming that even short-term culture confers or selects for immature progenitors with enough plasticity to elaborate neuronal phenotypes usually inhibited in vivo by the local microenvironment. The range of phenotypes generated from neuronal precursors in vitro now includes the peptides found in the neuroendocrine system: corticotropin-releasing hormone, growth hormone-releasing hormone, gonadotropin-releasing hormone, oxytocin, somatostatin, thyrotropin-releasing hormone, and vasopressin.

Key words: neurogenesis; neuroendocrine; cell culture; neurotransmitter; ventricular zone; hippocampus; hypothalamus; progenitor; neuropeptide; stem cell

\section{Introduction}

Postdevelopmental neurogenesis is conserved across evolutionary boundaries from crustaceans (Harzsch and Dawirs, 1996) to higher vertebrates including aves (Goldman and Nottebohm, 1983; Alvarez-Buylla, 1990), primates (Gould et al., 1999; Kornack and Rakic, 1999, 2001), and humans (Eriksson et al., 1998). In mammalian brains, adult neurogenesis is confined to two regions, the hippocampal dentate gyrus and the subependymal zone, which contributes neurons to the olfactory bulb (for review, see Gage, 2002; Rakic, 2002).

Progenitor cells can be isolated in culture from both the adult hippocampus and subependymal zone (Reynolds et al., 1992; Craig et al., 1996), and quiescent progenitors have been recovered from neurogenically silent regions such as the adult optic nerve and isocortex (Kirschenbaum et al., 1994; Palmer et al., 1999;

\footnotetext{
Received Sept. 10, 2003; revised Feb. 3, 2004; accepted Feb. 4, 2004.

This work was supported by National Institute of Neurological Disorders and Stroke Grant F32 NS10411 to E.A.M., National Institutes of Health (NIH) Grant AG19394 to P.R., and NIH Grants AG06088 and AG05131, The Christopher Reeve Paralysis Foundation, and The Lookout Fund to F.H.G. We are grateful for the expert technical assistance of S Forbes and B. Miller, and we thank J. Vaughan and W. W. Vale for providing antibodies to some neuroendocrine peptides. We are grateful to M. Wessendorf for the antibody to TRH. P. Sawchenko and C. Arias helped us to perform antibody-blocking controls with antigens generously provided by J. Rivier and J. Haycock. We thank M. L. Gage for editing this manuscript.

Correspondence should be addressed to Dr. Fred H. Gage, Laboratory of Genetics, The Salk Institute for Biological Studies, P.0. Box 85800, San Diego, CA 92186-5800. E-mail: gage@salk.edu.

D0I:10.1523/JNEUROSCI.4161-03.2004

Copyright $\odot 2004$ Society for Neuroscience $\quad 0270-6474 / 04 / 242886-12 \$ 15.00 / 0$
}

Kondo and Raff, 2000). These mixed progenitor cell cultures contain self-renewing, multipotent, stem-like cells and can be passaged through multiple population doublings. The neurons that result from these progenitors display a broad range of neuronal transmitter phenotypes, including neuropeptide $\mathrm{Y}$, GABAergic, dopaminergic, cholinergic, and serotonergic phenotypes (Palmer et al., 1997; Gage et al., 1998).

To better understand the range of neuronal subtypes that can arise from adult progenitor cells as well as their inherent limitations, we expanded our observations to include neuroendocrine phenotypes. Unlike the neurons of our previous studies, cells of hypothalamic neuroendocrine lineages produce unique peptide transmitters that are modulated by both traditional synaptic communication within the CNS and endocrine feedback. The neuroendocrine hypothalamus contains two distinct subsystems, the parvicellular and magnocellular systems, and the peptide profiles of these cells have been well described (for review, see Swanson, 1987). The six classically recognized parvicellular-releasing hormones are: corticotropin-releasing hormone $(\mathrm{CRH})$, dopamine [DA; characterized by expression of DOPA-synthesizing enzyme tyrosine hydroxylase (TH)], growth hormone-releasing hormone $(\mathrm{GRH})$, gonadotropin-releasing hormone (GnRH), somatostatin (SS), and thyrotropin-releasing hormone (TRH). The two magnocellular peptides are oxytocin (OXY) and vasopressin (VAS). These peptides are not all unique to the hypothalamus and fall into three categories with respect to the hippocampus: 
Category I, those generated in both the hippocampus and the hypothalamus (CRH, SS); Category II, those generated in the hypothalamus but not the hippocampus (DA, GRH, TRH, OXY, VAS); and Category III, a peptide believed to be generated in neither hippocampus nor hypothalamus but in the olfactory placode $(\mathrm{GnRH})$. GnRH neurons migrate in to the hypothalamus during development.

For these studies, neural progenitor cultures were initiated from intact hippocampal formations (supplemental Fig. 1; available at www.jneurosci.org), tissue that is developmentally derived from the alar plate. The hippocampal cultures were compared with cultures initiated from the hypothalamus, a basal plate derivative that generates the majority of the neuroendocrine subtypes but does not exhibit adult neurogenesis (supplemental Fig. 1 ; available at www.jneurosci.org). Neuronal progenitor cultures from both regions converged to virtually indistinguishable morphological and lineage potentials; both were able to generate approximately equal numbers of neurons and glia. More surprisingly, hippocampal and hypothalamic cultures were equally able to generate neurons of each of the classic neuroendocrine peptides examined in this study, regardless of category.

\section{Materials and Methods}

\section{Anatomy}

The methods used to detect hypothalamic peptides in the rat brain have been described in detail previously (Markakis and Swanson, 1997) and are reviewed briefly here.

Colchicine. Seven-week-old male Sprague Dawley rats were deeply anesthetized and placed in a stereotaxic instrument. The skull was exposed, and coordinates for bregma were taken with the nose bar at +4.0 $\mathrm{mm}$. Coordinates for injection into the lateral ventricle (derived from Swanson, 1998) were: anteroposterior $-0.8 \mathrm{~mm}$, mediolateral $+1.2 \mathrm{~mm}$, and dorsoventral $-4.0 \mathrm{~mm}$. A hole was drilled in the skull at these coordinates, and the bone was removed. Colchicine ( $4 \mathrm{mg} / \mathrm{ml}$ in sterile saline) was administered with a microsyringe using gravity and the difference between atmospheric and intracranial pressure as a driving force.

Perfusion. Forty-eight hours after colchicine administration, animals were anesthetized with sodium pentobarbitol $(50 \mathrm{mg} / \mathrm{kg}$, i.p. $)$ and perfused transcardially with $200 \mathrm{ml}$ of warm $0.9 \% \mathrm{NaCl}$, followed by two ice-cold solutions of $4 \%$ paraformaldehyde, $250 \mathrm{ml}$ of $\mathrm{pH} 6.5$ and $450 \mathrm{ml}$ of $\mathrm{pH} 9.5$, respectively. Brains were removed and postfixed for $24 \mathrm{hr}$ in $4 \%$ paraformaldehyde, $\mathrm{pH} 9.5$, and $10 \%$ sucrose. They were then blocked and quick frozen in cooled isopentane and stored with ice in a $-70^{\circ} \mathrm{C}$ freezer until they were sectioned. Serial sections, $15 \mu \mathrm{m}$ thick, were cut on a sliding microtome and stored at $-20^{\circ} \mathrm{C}$ in cryoprotectant until they were stained.

Immunohistochemistry. Sections were rinsed of cryopotectant in $0.02 \mathrm{M}$ potassium PBS (KPBS) two times for $10 \mathrm{~min}$ each and incubated in KPBS with Triton X-100 (0.3\%; KPBS+) and normal donkey serum $(200 \mu \mathrm{l}$ in $10 \mathrm{ml}$ ) for $1 \mathrm{hr}$. Sections were incubated in primary antibodies for neuroendocrine peptides (see below; all primary antisera for neuroendocrine peptides were produced in rabbit) in KPBS + for $72 \mathrm{hr}$ at $4^{\circ} \mathrm{C}$ and then rinsed in KPBS. Sections were then incubated with donkey- $\alpha$-rabbit Rhodamine RedX (711-295-152; Jackson ImmunoResearch, West Grove, PA) and diluted 1:250 in KPBS + for $1 \mathrm{hr}$ at room temperature. Finally, sections were rinsed in KPBS (two times for 10 min each) and mounted on gel-coated glass slides and coverslipped using polyvinyl alcohol-1,4-diazabicyclo-[2.2.2] octane (DABCO) mountant.

Confocal microscopy. Sections were examined using a Zeiss (Thornwood, NY) laser scanning microscope (LSM) 510 Meta laser-scanning microscope equipped with a multiphoton laser attached to a Zeiss Axiovert $100 \mathrm{M}$ microscope equipped with standard filter sets to visualize Rhodamine and UV-excitable fluorophores. The microscope was driven by a Fujitsu (Sunnyvale, CA) computer running Zeiss LSM 510 acquisition software. Sections were examined for the presence (hypothalamus) or absence (hippocampus) of neuroendocrine peptide staining.

\section{Cell culture}

The methods used to produce hippocampal progenitor cell cultures have been described in detail previously (Gage et al., 1995; Palmer et al., 1995, 1999) and are reviewed briefly here. The same methodology was used to produce hypothalamic progenitor cultures.

Animals. Seven-week-old Fisher 344 male rats (Harlan Sprague Dawley, Indianapolis, IN) were deeply anesthetized and decapitated, and brains were removed and placed in cold $\left(4^{\circ} \mathrm{C}\right)$ sterile PBS plus glucose on ice.

Tissue dissection. Brains were dissected in a hood, and both hippocampal formations were removed for the hippocampal cultures (supplemental Fig. 1; available at www.jneurosci.org). The remaining ventral brain was sectioned with a scalpel into rostral, mid, and caudal levels. The third ventricle, with surrounding ventricular zone, and some medial zone tissue were harvested from each level for the hypothalamic cultures (supplemental Fig. 1; available at www.jneurosci.org).

Tissue dissociation and fractionation. Tissues were minced and digested in a solution of papain, neutral protease, and DNase in HBSS. Cells were spun and washed three times in DMEM with 10\% FBS and filtered through sterile nylon mesh. The resulting cell suspension was mixed with Percoll and saline and fractionated by centrifugation for $30 \mathrm{~min}$ at $20,000 \times g$ at $18^{\circ} \mathrm{C}$. The progenitor cell fraction was harvested and washed free of Percoll and plated on polyornithine-laminin-coated dishes in growth medium consisting of DMEM/F12 (1:1) high glucose with N2 supplement (Invitrogen, Gaithersburg, MD) and $20 \mathrm{ng} / \mathrm{ml} \mathrm{re-}$ combinant human fibroblast growth factor-2 (FGF-2) prepared in E. coli (Peprotech, Rocky Hill, NJ). Cells were maintained for their first $24 \mathrm{hr}$ in this growth medium, plus $10 \%$ FBS, and subsequently grown in serumfree media. Seventy-five percent of the media was replaced with new growth media every $48 \mathrm{hr}$. Cultures were passaged at confluence using trypsin-EDTA solution (Irvine Scientific, Santa Ana, CA) and replated at half of their original density in growth medium with $30 \%$ conditioned medium.

Differentiation of cultures. Two differentiation media were used sequentially. They were made of growth media plus $1 \%$ FBS with either 100 $\mathrm{ng} / \mathrm{ml}$ all-trans retinoic acid (RA) or $5 \mu \mathrm{M}$ forskolin (F). Cultures were differentiated with RA medium for 1 week, followed by 1 week of F differentiation. Cells were differentiated in coated dishes until $48 \mathrm{hr}$ before fixation, at which point they were passaged onto polyornithinelaminin-coated glass multiwell slides (Fisher Scientific, Houston, TX). Cells were fixed in $4 \%$ paraformaldehyde, $\mathrm{pH} 9.5$, for $10 \mathrm{~min}$.

Immunocytochemistry. The immunostaining protocol is a variant of a biotinylated tyramide amplification system (BLAST) protocol provided by Dr. Richard Simerly (Oregon Regional Primate Research Center, Beaverton, OR) using the BLAST kit from PerkinElmer Life Sciences (Boston, MA). Cells were rinsed briefly in KPBS (two times for 10 min each) and incubated in KPBS+ for $1 \mathrm{hr}$ at room temperature. Cells were incubated in primary antibodies diluted in KPBS+ (at concentrations indicated below) for $72 \mathrm{hr}$ at $4^{\circ} \mathrm{C}$. Cells were then rinsed in KPBS and incubated in secondary antibodies $\alpha$-biotin and $\alpha$-FITC for $1 \mathrm{hr}$ at room temperature. Cells were rinsed again in KPBS and then incubated in streptavidin-HRP 1:500 in KPBS-blocking solution (KPBS-B made of 50 $\mathrm{ml}$ of $\mathrm{KPBS}$ and $0.25 \mathrm{gm}$ of blocking agent heated to $60^{\circ} \mathrm{C}$ until dissolved) for $30 \mathrm{~min}$. Cells were again rinsed in KPBS and then incubated in cyanine 3-tyramide 1:50 in $1 \times$ amplification diluent for $10 \mathrm{~min}$. Another rinse in KPBS was followed by a 15 min incubation in $1 \% \mathrm{H}_{2} \mathrm{O}_{2}$ in $\mathrm{KPBS}$ to deactivate HRP. Cells were again rinsed in KPBS and then incubated in antifluorescein-HRP conjugate 1:50 in KPBS+ for $30 \mathrm{~min}$. Cells were again rinsed in KPBS and then incubated in fluorescein-tryamide 1:50 in $1 \times$ amplification diluent for $10 \mathrm{~min}$. Cells were coverslipped using PVA-DABCO after a final rinse in KPBS.

Antibodies. Some of the antibodies used were not commercially available. All have been characterized and are specific on the basis of absorption with specific antigen and, in some cases, radioimmunoassay. The $\alpha$-CRH antibody was the rabbit C-70 polyclonal antibody, which was absorbed with human $\alpha$-globulin, $\alpha$-MSH, and neuropeptide EI, used at $1: 1000$ (Sawchenko, 1987); the $\alpha-\mathrm{GnRH}$ was a rabbit polyclonal antibody number 44 absorbed with human $\alpha$-globulin and used at 1:4000 (Simerly et al., 1986); $\alpha$-GRH was the rabbit G-75 polyclonal antibody absorbed 
with human $\alpha$-globulin and used at 1:6000 (Sawchenko et al., 1985). These three antibodies were gifts from Wylie W. Vale (The Salk Institute, La Jolla, CA). For TRH staining, we used the rabbit polyclonal antibody to pre-pro TRH at 1:5000, a gift from Martin Wessendorf (University of Minnesota, Minneapolis, MN) (Wessendorf et al., 1990). We stained for the neuronal nuclear antigen NeuN using the mouse monoclonal antibody (a hybridoma supernatant used at 1:20; provided by R. Mullen, University of Utah, Salt Lake City, UT) (Mullen et al., 1992).

The remaining antibodies are commercially available. The $\alpha$-glial fibrillary acidic protein (GFAP) antibody is a guinea pig antibody from Advanced Immunochemical (Long Beach, CA), which we used at 1:500 (031223) (Palmer et al., 2000). The $\alpha$-SS antibody is a rabbit polyclonal from Immunostar (20067; Hudson, WI) used at 1:2000 (Markakis and Swanson, 1997). $\alpha$-TH was a rabbit polyclonal from Pel-Freeze Biologicals (P40101-0; Rogers, AR) used at 1:1000 (Markakis and Swanson, 1997). The $\alpha$-OXY and $\alpha$-VAS antibodies were rabbit polyclonal antibodies from Chemicon (Temecula, CA; AB 911 and AB 1565, respectively) used at 1:2000 (Simerly and Swanson, 1987). We stained immature neurons using the antibody to TUJ-1 (class III $\beta$-tubulin), a mouse monoclonal antibody from Babco (MMS-435P; Richmond, CA) that we used at 1:5000 (Palmer et al., 2000). Additional neuronal staining was performed with the antibody to Map2abc from Sigma (M4404; St Louis, MO) that we used at 1:5000 (Palmer et al., 2000).

Absorption with specific antigen. Antibodies labeling the neuroendocrine peptides have been extensively characterized on rat tissue and, in our study, the immunohistochemistry resulted in characteristic groups of labeled cells as previously described in the literature. However, with the exception of the antibody to $\mathrm{TH}$, these antibodies have not been used to label cells in progenitor cultures. To asses the specificity of our immunocytochemical labeling, we preabsorbed the antibodies with specific antigen using a protocol kindly provided by Paul Sawchenko (The Salk Institute). Antigens, generously provided by Jean Rivier (The Salk Institute) and John W. Haycock (Louisiana State University, New Orleans, LA) were dissolved in KPBS. Those that did not go into solution with ease ( $\mathrm{CRH}, \mathrm{GRH}, \mathrm{OXY}$ ) were subjected to heat to $60^{\circ} \mathrm{C}$ in a water bath. In addition, OXY required the introduction of $\mathrm{NaOH}$ fumes to go into solution. In general, $100 \mu \mathrm{l}$ of peptide solution at a concentration of 1 $\mathrm{mg} / \mathrm{ml}$ was diluted in $100 \mu \mathrm{l}$ of KPBS with $1 \mu \mathrm{l}$ of antibody and left overnight. Blocked antibody solutions were brought up to working antibody concentrations the next day and were used on tissue and cells to determine specificity of label. Secondary antibody labeling was performed as described above. Negative controls were performed by excluding antibody, and positive controls were performed by replacing peptide solutions with KPBS. For each of the antibodies used, blocking with specific antigen abolished labeling on both tissue and cells, and no labeling was detected above background levels.

Confocal microscopy. Immunolabeled cultured cells were examined under a Bio-Rad (Hercules, CA) MRC 1024 UV confocal microscope using Krypton and Argon ion lasers attached to a Zeiss (Thornwood, NY) Axiovert $135 \mathrm{M}$ microscope equipped with standard filter sets to visualize Texas Red and FITC. The confocal microscope was driven by a computer (Prosignia 500; Palo Alto, CA) running Bio-Rad Lasersharp 2.1 software. Images were evaluated for the presence or absence of singly (neuropeptides) and doubly (neuroendocrine peptides and a neuronal antigen) labeled cells.

Nonquantitative real time-PCR. Total RNA was isolated from cultured cells using RNAzol (Tel Test, Friendswood, TX), and cDNA was made using the Superscript II preamplification system (Invitrogen) from $4 \mu \mathrm{g}$ of total RNA. First strand cDNA was diluted 2.5-fold, and 2-8 $\mu \mathrm{l}$ of cDNA was used for each PCR reaction. Real time (RT)-PCR products were analyzed simply for the presence or absence of product in an agarose gel containing ethidium bromide. Appropriate water and minus RT controls were run for each experiment. Two sets of hippocampal and hypothalamic undifferentiated and differentiated cultures were analyzed. The following oligonucleotides were used: CRH, 356bp product $\left(5^{\prime}\right) \mathrm{GAA}$ TTT CTT GCA ACC GGA GC ( $\left.3^{\prime}\right)$ CTC AGA AGG TGG AAG GTG AGA T; TRH, 524bp product $\left(5^{\prime}\right)$ CCT GGA TCA CAA AAC GCC A (3')ACT TGT GGG CTT TGC TTC.

Real time quantitative PCR. Gene expression was verified by quantita- tive RT-PCR (Q-PCR). Total RNA was prepared from cultured cells using the RNA-Bee Isolation Solvent (Tel Test). cDNA was prepared from $2 \mu \mathrm{g}$ of total RNA, using Superscript First-Strand cDNA Synthesis System (Invitrogen). Primers were designed using Primer Express v1.5 software (Applied Biosystems, Foster City, CA) and synthesized by Allele Biotechnology and Pharmaceuticals (San Diego, CA). Q-PCR was performed with one twenty-fifth of the cDNA resulting from the Superscript reaction using the SYBR Green Master Mix (Applied Biosystems) and 0.2 $\mu \mathrm{M}$ of each primer in a $25 \mu \mathrm{l}$ reaction. All reactions were performed in triplicate using an ABI Prism 7700 Sequence Detection System (Applied Biosystems). Data analysis was performed according to the protocol provided by Applied Biosystems using Sequence Detector Systems v1.7 software. RNA extracted from the entire rat CNS (brain and spinal cord) was used as a positive control sample that contains transcripts from all neuronal and glial cell types of the adult CNS. This control cDNA was used to create standard curves representing standardized samples containing a low abundance yet authentic transcript for each gene. Expression of each gene relative to this standard was calculated on the basis of the standard curve for a given primer set. The relative amount of calculated message was normalized to the level of a control gene (18 sec rRNA) to control for inter-sample variation in amplification efficiency. In all cases, PCR product was evaluated at the final cycle and shown to contain a single product of the expected melting point.

Field counts. Field counts of peptide immunolabeled cells from hypothalamic cultures at passage 5 were performed to obtain an approximate idea of the percentage of peptide-positive neuron numbers in undifferentiated and differentiated cultures as well as to reveal information on the distribution of the cells. Nonadjacent microscope fields were chosen under a $40 \times$ objective on slides that were stained for CRH, GnRH, GRH, or $\mathrm{TRH}$, and in addition, in differentiated cultures, TUJ-1. All counts met one of two criteria. Subsequent nonadjacent fields in undifferentiated cultures were analyzed until $\geq 100$ cells total were counted. Differentiated cultures produced considerably more neurons, and at least three fields were counted. Singly (peptide, undifferentiated) and doubly (peptide plus TUJ-1, differentiated) labeled cells were scored, and the average number of these cells was determined in each of two separate counts for differentiated cultures.

\section{Results}

\section{Anatomy}

Rat brain sections throughout the rostrocaudal extent of the hypothalamus and hippocampus were immunostained for the eight classic neuroendocrine peptides. Absorption with specific antigen blocked all immunohistochemical peptide labeling. Peptidepositive cells were detected under a confocal microscope, and hypothalamic populations were mapped using an atlas of the rat brain (Swanson, 1998). In every case, the location of immunopositive neurons was consistent with the anatomical mapping of these peptides described in the literature and is summarized by peptide below. Cells producing the Category I neuropeptides $\mathrm{CRH}$ and SS were found in small numbers in the hippocampal formation and in the hypothalamus (Figs. 1,2). Cells producing the Category II and III neuropeptides were found exclusively in the hypothalamus, and examples of their exclusion from the hippocampal formation can be found in Figure 2.

\section{Cell culture}

As one might expect of tissues containing an extensive periventricular zone, the tissue harvested from the hypothalamus was a rich source of neural progenitors. Hypothalamic cultures were established in parallel to hippocampal progenitor cultures and carried for $\sim 10$ population doublings (five to seven passages). These cultures were neither immortalized nor subcloned and extensively expanded. Evaluations were performed at low passage numbers to avoid frank transformation and aneuploidy common to extensively passaged culture (Palmer et al., 1997). Bulk popu- 


\section{Corticotropin-Releasing Hormone}
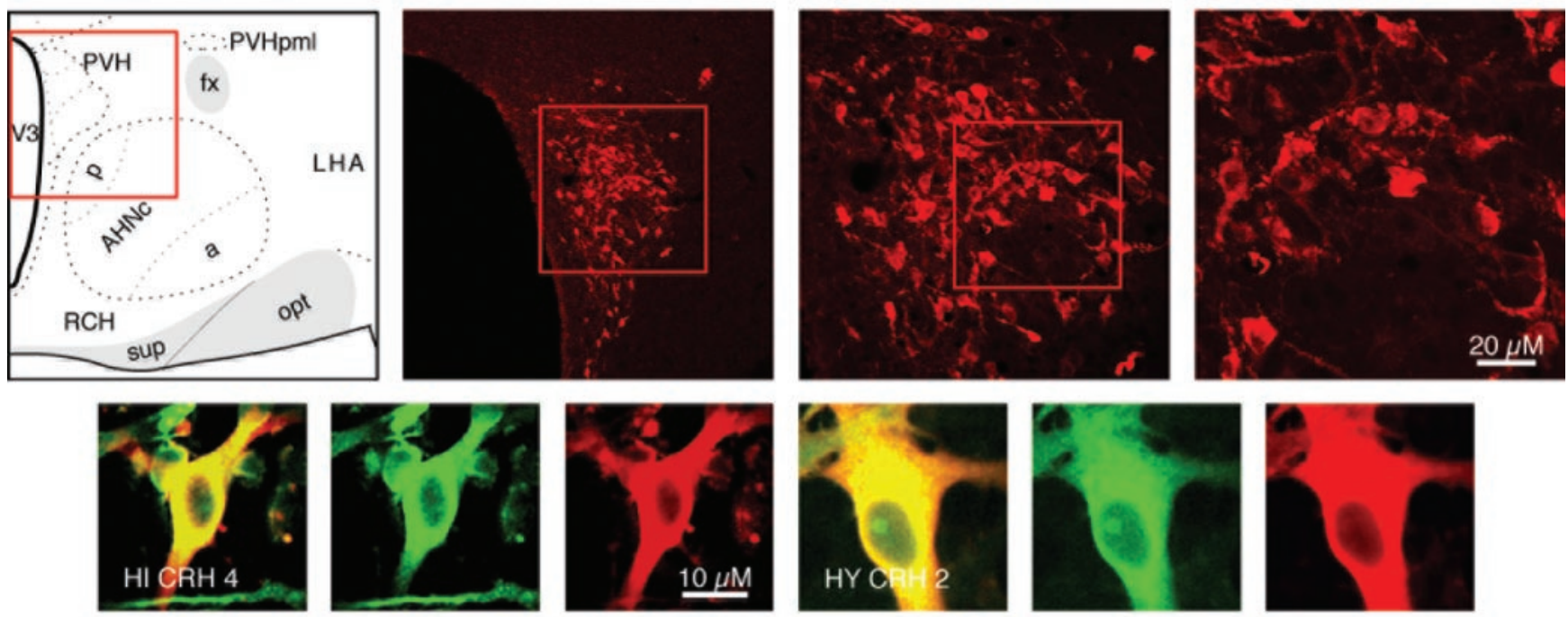

\section{Somatostatin}
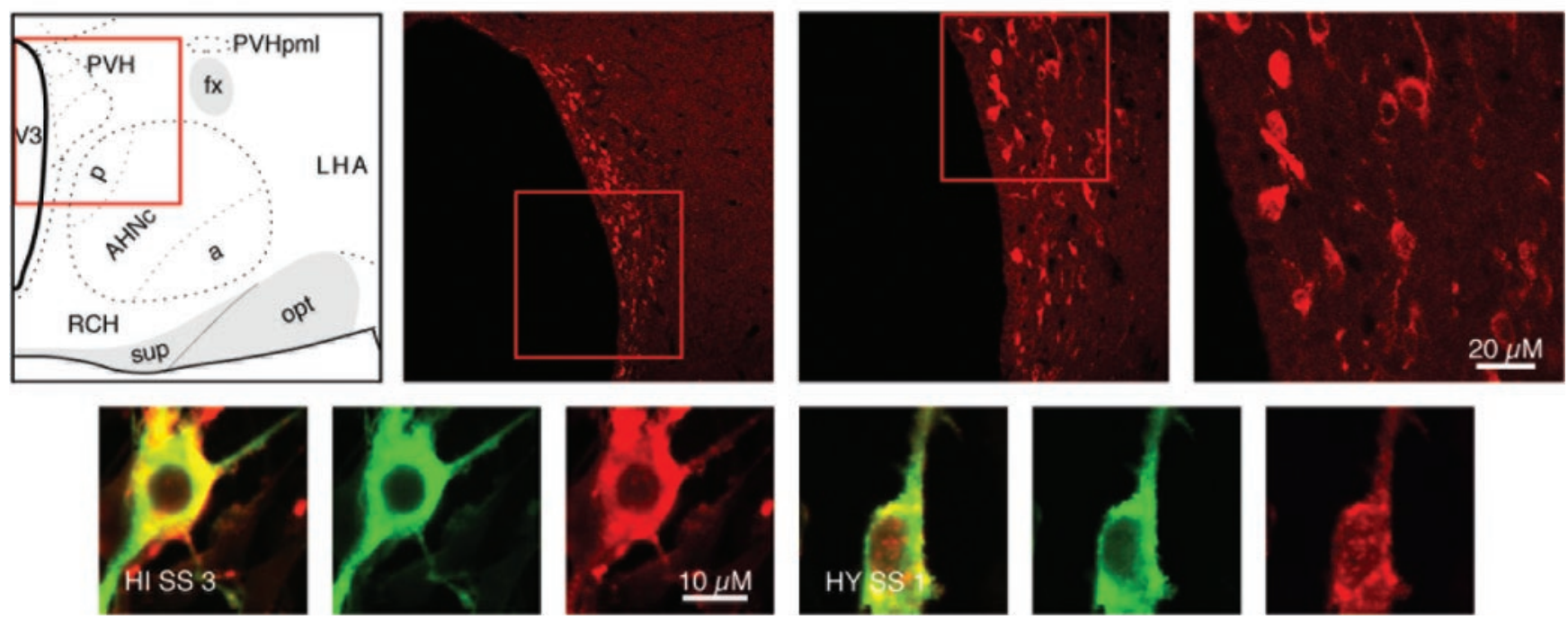

Figure 1. Category I neuropeptides CRH and SS. Confocal photomicrographs in the top rows are rat brain sections stained with the antibody to CRH and SS, respectively. At left is an atlas graphic (Swanson, 1998) indicating the approximate location within the hypothalamus. In each image, the red box serves to orient the location of higher magnification images that follow. In the second row are two sets of three confocal photomicrographs of immunocytochemistry for the neuropeptide (red) and TUJ-1 (green) double-labeled (merged) cells detected in differentiated adult progenitor cultures of hippocampal (HI) and hypothalamic (HY) origins. AHNa,c,p, Anterior hypothalamic nucleus anterior, central, posterior parts; fx, columns of the fornix; LHA, lateral hypothalamic area; opt, optic tract; PVHpml, paraventricular nucleus hypothalamus posterior magnocellular part lateral zone; $\mathrm{RCH}$, retrochiasmatic area; sup, supraoptic commisures; $\mathrm{V3}$, third ventricle.

lations (rather than clones) were evaluated to avoid the potential reporting of a phenomenon that may have been restricted to an extremely rare subset of cells, which may have been enriched via cloning. As we observed in previous studies, precursor cultures isolated from different brain regions tend to converge morphologically and, in their generic ability, generate neurons and glia (supplemental Fig. 1; available at www.jneurosci.org). We also observed that precursors isolated from brain regions of different embryonic origins converge to yield indistinguishable progenitor cultures capable of producing a wide variety of neuronal subtypes, again unrestricted by their plate of origin.

Initial plating densities of the cultures differed somewhat, with hippocampal cultures being generated from approximately twice as much tissue, plating at approximately twice the density of hypothalamic cultures. At passage 4 and beyond, hypothalamic cultures were morphologically indistinguishable from hippocampal cultures. Phenotypically, both hippocampal and hypo- thalamic cultures maintained under growth conditions contained very few GFAP-positive astrocytes or type $3 \beta$-tubulin (TUJ-1) (Menezes and Luskin, 1994)-positive neurons $(<1$ in 10,000 cells). As we described previously, growth factor withdrawal followed by retinoic acid stimulation is sufficient to stimulate a low level of spontaneous differentiation with up to $5-10 \%$ of the cells expressing $\beta$-tubulin. Similarly, both hippocampal and hypothalamic cultures produced between $\sim 0.5$ and $5 \%$ immature neurons when induced to differentiate, with the absolute number of neurons increasing with the number of days cells were exposed to the differentiation conditions. Neurons were detected in differentiated cultures by immunocytochemistry using the antibodies against NeuN, TUJ-1, and Map2abc (supplemental Fig. 1; available at www.jneurosci.org). Triple immunocytochemical staining for the early neuronal antigen TUJ-1 and each neuroendocrine peptide (CRH, GnRH, GRH, OXY, SS, TH, TRH, and VAS) along with the glial marker GFAP was performed on differ- 


\section{Hippocampal Staining}
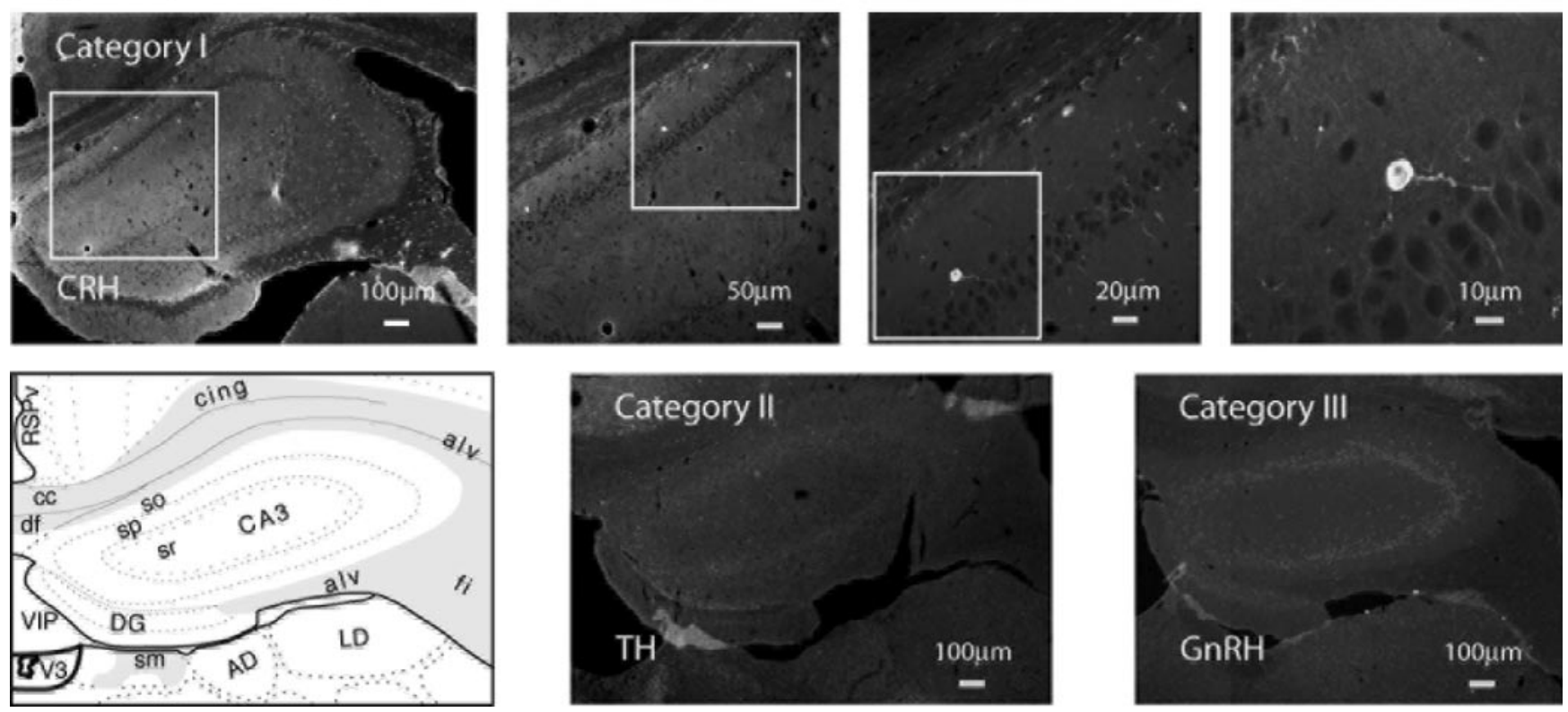

Figure 2. Hippocampal staining. Confocal photomicrographs and montages of immunohistochemistry for neuroendocrine peptides of each generative category in the hippocampus. In the top row, the Category I peptide CRH is shown. At left is a photo-montage of two low-power confocal images. In each image, the box serves to orient subsequent higher-power images. At lower left is an atlas graphic (Swanson, 1998) indicating the approximate level of the hippocampus in all images. Category II and III neurons producing TH and GnRH, respectively, were absent in the hippocampus, as shown in their photo-montages. In all three images, background was enhanced to show tissue details. AD, Anterodorsal nucleus thalamus; alv, alveus; CA3so,sp,sr, field CA3 stratum oriens, pyramidal layer, stratum radiatum; cing, cingulum bundle; cc, corpus calosum; df, dorsal fornix; DG, dentate gyrus; fi, fimbria; LD, lateral dorsal nucleus thalamus; $R S P V$, retrosplenial area ventral part; sm, stria medularis; V3, third ventricle; VIP, velum interpositum.

entiated cultures, whereas a subset of peptide markers was evaluated on undifferentiated cultures. Results are presented below by generative category.

\section{Category I: cell types generated in both the hippocampus and hypothalamus}

\section{$\mathrm{CRH}$}

Neurons that release CRH into portal blood increase adrenocorticotropic hormone secretion and are centered in the lateral zone of the medial parvicellular part of the paraventricular nucleus of the hypothalamus (PVH) (Bloom et al., 1982; Swanson et al., 1983) (Fig. 1). Neurons that were both CRH positive and TUJ-1 positive were detected in differentiated hypothalamic cultures and in differentiated hippocampal cultures (Fig. 1). CRH fibers have been described in the hippocampus, and very few $\mathrm{CRH}$ producing neurons have been reported there as well (Fig. 2). From a total of 117 cells examined in undifferentiated hypothalamic cultures, $17 \mathrm{CRH}$-positive cells were detected (Fig. 3). In differentiated cultures, $114 \mathrm{CRH}$ and TUJ-1 double-labeled neurons were detected from a total of $366 \beta$-tubulin-positive neurons counted; an average of two separate field counts is shown in Figure 4 .

\section{SS}

Neuroendocrine SS cells inhibit growth hormone secretion and are found in the anterior periventricular nucleus and the periventricular part of the PVH (Elde and Parsons, 1975; Parsons et al., 1976) (Fig. 1). Cells that were doubly labeled for SS and TUJ-1 were found in both differentiated hypothalamic and hippocampal cultures (Fig. 1).
Category II: cell types generated in the hypothalamus but not in the hippocampus

\section{Dopamine}

Neuroendocrine dopaminergic neurons inhibit prolactin release and are located medially in the arcuate nucleus of the hypothalamus (ARH) (Chan-Palay et al., 1984). There is also a small dopaminergic cell group within the PVH (Swanson et al., 1981) (Fig. 5). Differentiated hypothalamic and hippocampal cultures produced TUJ-1-positive neurons that were also TH positive (Fig. 5). The production of dopaminergic neurons by adult hippocampal progenitors indicates that these alar plate derivatives can produce neurons not found in their tissue of origin. An example of the absence of Category II staining in the hippocampus in general, and of TH neurons specifically, can be found in Figure 2 .

\section{GRH}

GRH neurons increase growth hormone secretion and are centered in the lateral parts of the ARH (Bloch et al., 1983; Sawchenko et al., 1985) (Fig. 5). Neurons that produce GRH were generated by differentiated hypothalamic and hippocampal cultures (Fig. 5). Field counts in undifferentiated hypothalamic cultures detected $56 \mathrm{GRH}$-positive neurons from a total of 125 cells examined (Fig. 3). Counts in differentiated cultures resulted in a total of 117 GRH and TUJ-1 double-labeled neurons from 236 neurons counted; average numbers per count are shown in Figure 4. The detection of GRH-positive neurons in hippocampal progenitor cultures indicates that these progenitors can produce types of neurons not found in their tissue of origin.

\section{TRH}

Neurons that release TRH into portal blood cause an increase in thyroid-stimulating hormone production by the anterior pitu- 

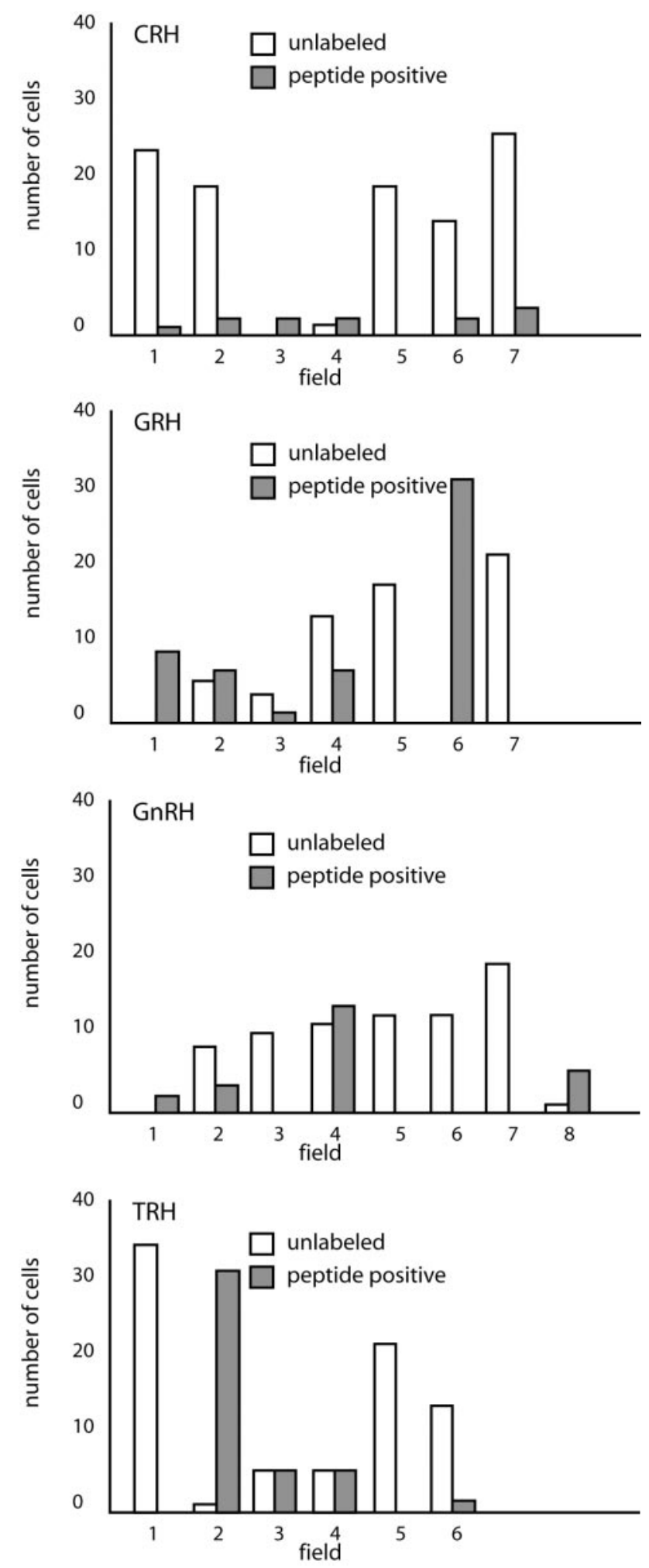

Figure 3. Undifferentiated hypothalamic field counts. This graphic representation of the numbers of peptide-positive neurons producing CRH, GnRH, GRH, or TRH detected in undifferentiated hypothalamic cell cultures per field shows the distribution of these cells that seem to be found in clusters.

itary and are centered in the medial parvicellular part of the PVH (Brownstein et al., 1982; Lechan and Jackson, 1982) (Fig. 6). Neurons that stained for TUJ-1 and TRH were generated by both differentiated hypothalamic and hippocampal cultures (Fig. 6),

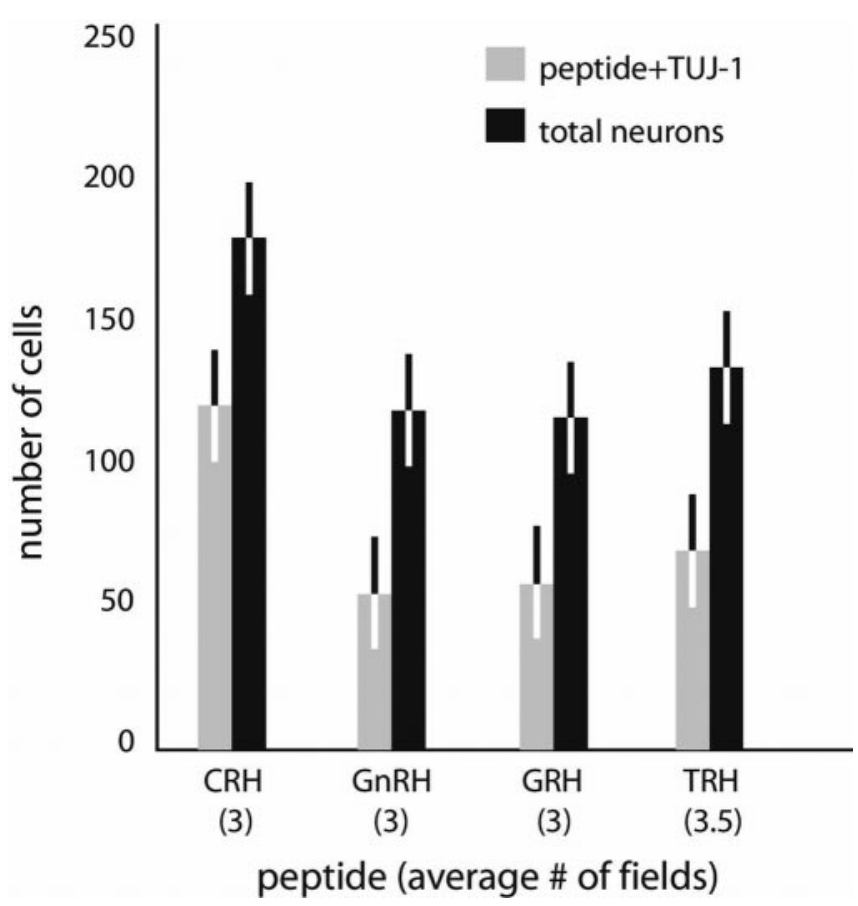

Figure 4. Differentiated hypothalamic neuron numbers. Average numbers of peptide and TUJ-1 double-labeled neurons versus total neurons detected in differentiated hypothalamic cultures are shown by peptide for $\mathrm{CRH}, \mathrm{GnRH}, \mathrm{GRH}$, or TRH. Bars represent SD from the two counts. Three fields were tallied per count, with the exception of TRH, in which 3.5 fields were scored.

and TRH-positive cells were also detected in undifferentiated cultures of both types. Forty-two TRH-positive cells were detected from 123 cells examined in undifferentiated cultures (Fig. 3). In differentiated hypothalamic cultures, 140 cells were double-labeled for TRH and TUJ-1 from a total of 271 neurons examined (averages in Fig. 4). Like all other Category II neurons, TRH neurons are not found in the hippocampal formation, and their production by hippocampal progenitors again indicates that progenitors can produce neurons of phenotypes not found in their tissue of origin.

\section{$O X Y$}

Neuroendocrine neurons that release OXY onto the vasculature of the posterior pituitary affect smooth muscle in the uterus and mammary glands and are located in the supraoptic and accessory supraoptic nuclei and in the PVH (Swanson and Sawchenko, 1983) (Fig. 6). Cells that were both OXY positive and TUJ-1 positive were detected in both differentiated hypothalamic and hippocampal cultures (Fig. 6).

\section{VAS}

Vasopressinergic neurons in the hypothalamus cause constriction of smooth muscle in the vasculature and of renal tubules, and these neurons are centered in the supraoptic and accessory supraoptic nuclei as well as in the PVH (Swanson and Sawchenko, 1983) (Fig. 7). Such neurons were produced by both hypothalamic and hippocampal differentiated cultures (Fig. 7).

\section{Category III: cell type generated in the olfactory placode}

GnRH

The neurons that produce GnRH stimulate gonadotropin release and are centered in and around the rostral tip of the periventricular zone, predominantly in the medial septal-diagonal band com- 


\section{Dopamine (tyrosine hydroxylase immunoreactivity)}
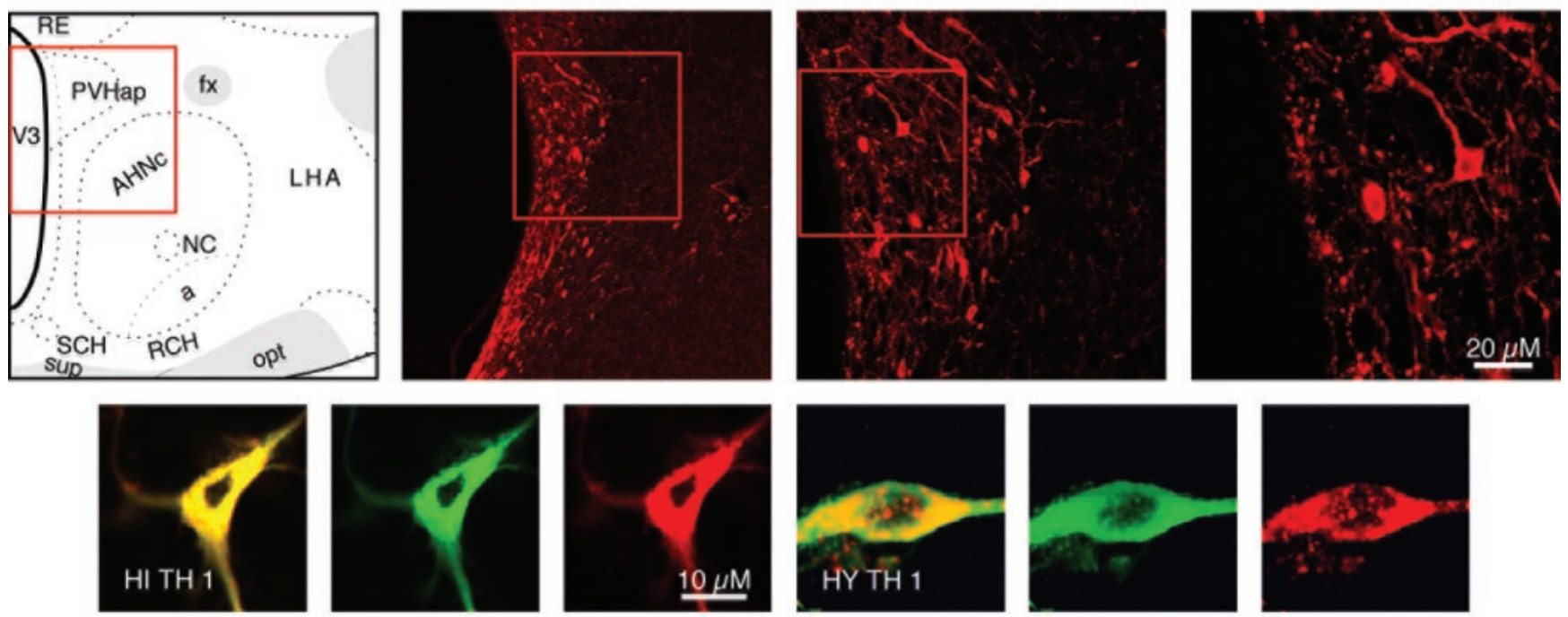

\section{Growth Hormone-Releasing Hormone}
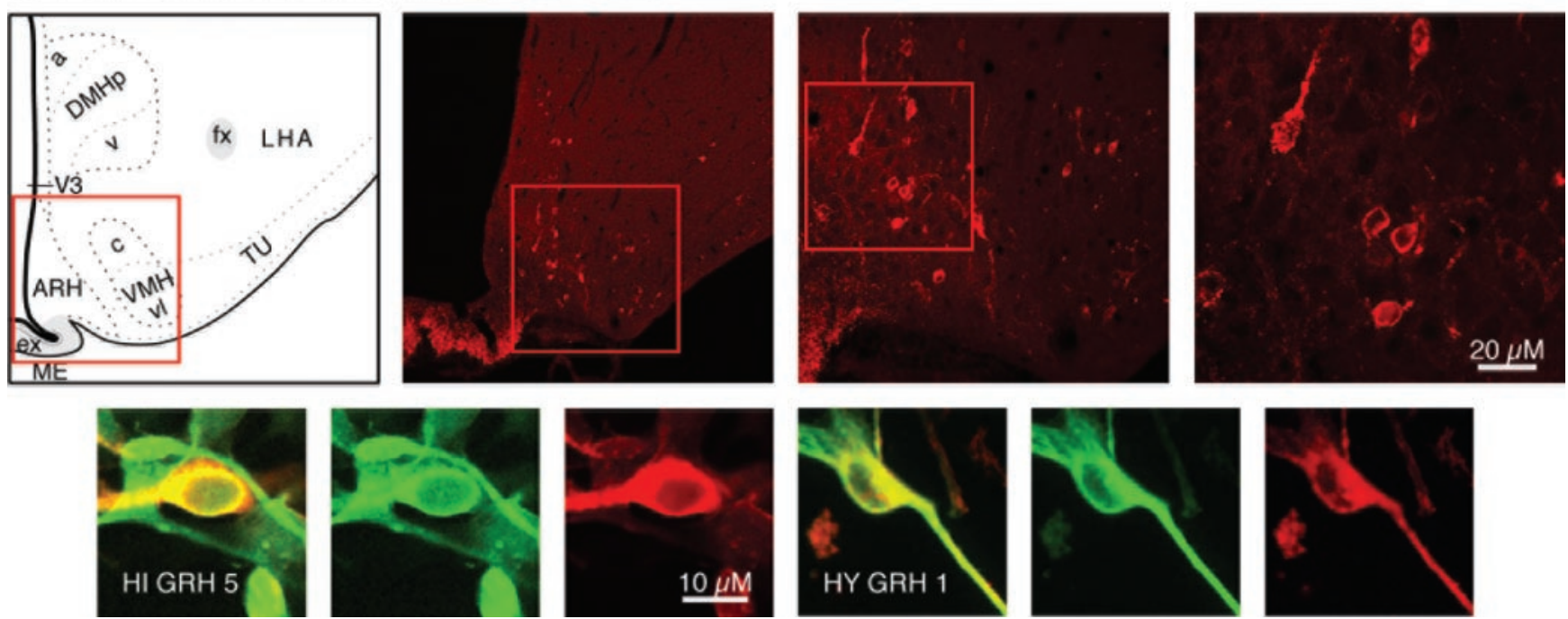

Figure 5. Category II neuropeptides DA and GRH. Confocal photomicrographs in the top rows are rat brain sections stained with the antibody to TH and GRH, respectively. At left is an atlas graphic (Swanson, 1998) indicating the approximate location within the hypothalamus. In each image, the red box serves to orient the location of higher magnification images that follow. In the second row are two sets of three confocal photomicrographs of immunocytochemistry for the neuropeptide (red) and TUJ-1 (green) double-labeled (merged) cells detected in differentiated adult progenitor cultures of hippocampal (HI) and hypothalamic (HY) origins. AHNa,c, Anterior hypothalamic nucleus anterior, central parts; DMHa, p,v, dorsomedial nucleus hypothalamus anterior, posterior, ventral parts; fx, columns of the fornix; LHA, lateral hypothalamic area; MEex, median eminence external lamina; NC, nucleus circularis; opt, optic tract; PVHap, paraventricular nucleus hypothalamus anterior, parvicellular part; $\mathrm{RCH}$, retrochiasmatic area; RE, nucleus reuniens; $\mathrm{SCH}$, suprachiasmatic nucleus; sup, supraoptic commisures; TU, tuberal area; V3, third ventricle; $\mathrm{VMHC}, \mathrm{Vl}$, ventromedial nucleus hypothalamus central, ventrolateral parts.

plex, the median preoptic nucleus, and the preoptic periventricular nucleus (Barry et al., 1973; Ibata et al., 1979; Bennett-Clarke and Joseph, 1982) (Fig. 8). Cells that were both GnRH positive and TUJ-1 positive were found in differentiated hippocampal and hypothalamic cultures (Fig. 8), and some GnRH-positive cells were also detected in undifferentiated hypothalamic and hippocampal cultures. In undifferentiated hypothalamic cultures, $26 \mathrm{GnRH}$ cells were counted from a total of 100 cells examined (Fig. 3). In differentiated hypothalamic cultures, a total of 62 GnRH and TUJ-1 double-labeled neurons were detected from a total of 240 neurons counted; averages of the field counts are shown in Figure 4. In rodents, GnRH neurons are believed to be generated solely in the olfactory placode; they migrate into the hypothalamus during development. Thus, the generation of GnRH neurons by either type of progenitor culture confirms that progenitors are freed of the constraints of their embryonic origins in generating neuronal subtypes in vitro.

Immunocytochemistry resulted in the detection of each neuroendocrine peptide sought with TUJ-1 in differentiated cultures derived from hypothalamic or hippocampal progenitors, regardless of generative category. In each culture, there were TUJ-1positive neurons that were not peptide positive, and there were peptide-positive neurons that did not label with TUJ-1 (Fig. 4), because neurons lose immunoreactivity for this marker as they mature. Although the numbers of peptide-positive neurons were far greater in differentiated cultures, some peptide-labeled cells were detected in undifferentiated cultures as well, because neurons can differentiate even without the benefit of differentiation media. Peptide-positive cells in undifferentiated cultures were GFAP negative. It is unlikely that the peptide-positive, TUJ-1- 


\section{Thyrotropin-Releasing Hormone}
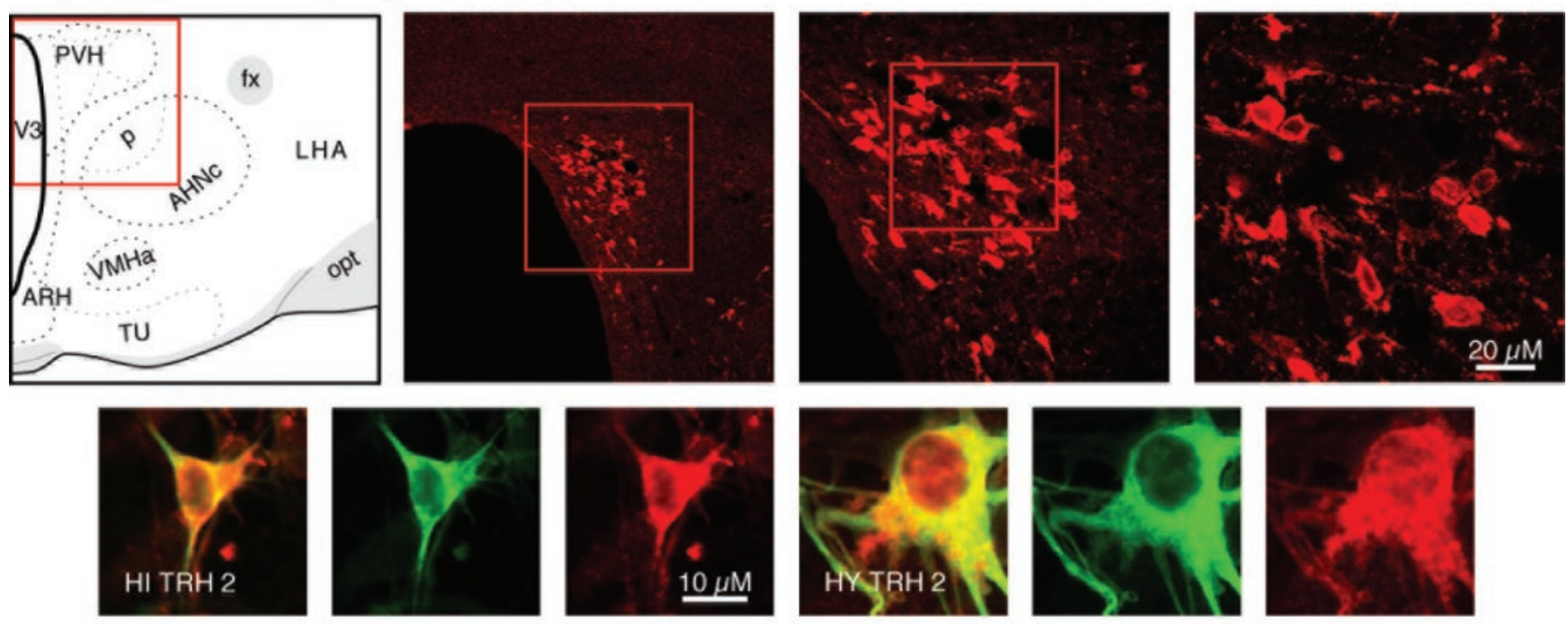

\section{Oxytocin}
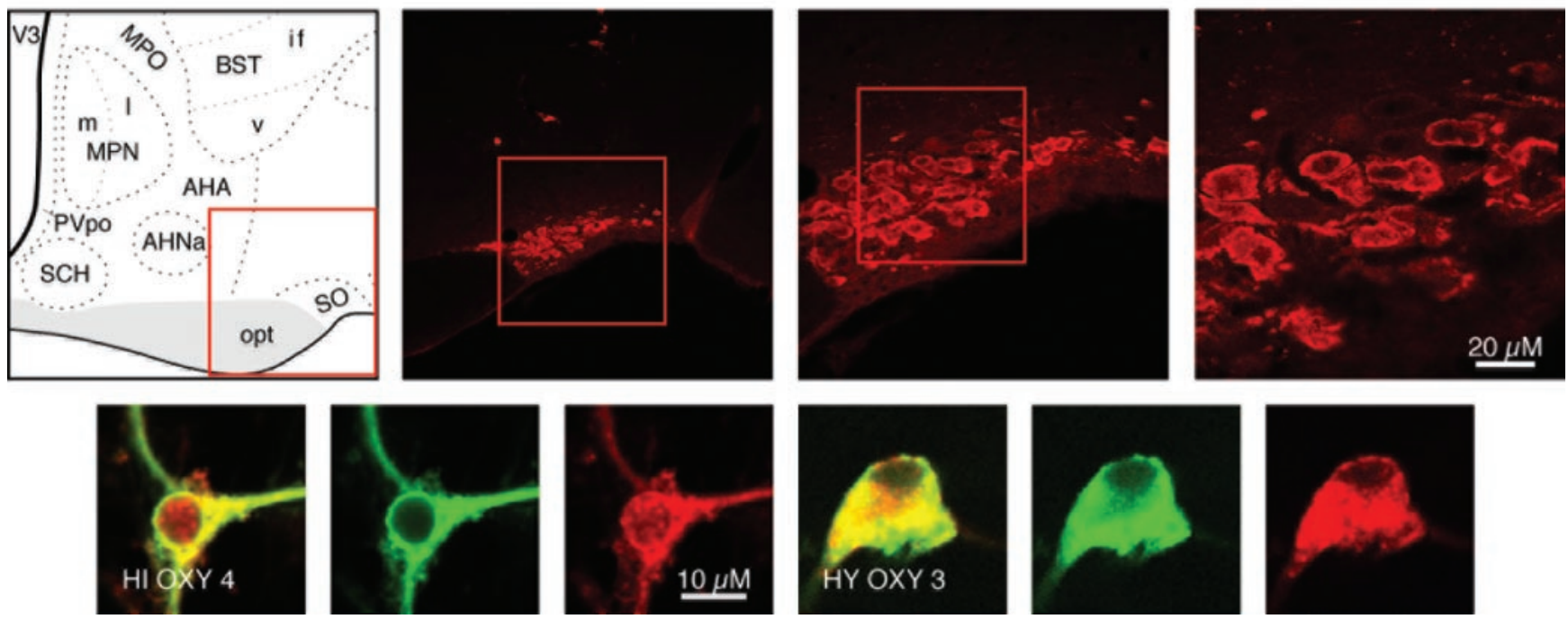

Figure 6. Category II neuropeptides TRH and OXY. Confocal photomicrographs in the top rows are rat brain sections stained with the antibody to TRH and OXY, respectively. At left is an atlas graphic (Swanson, 1998) indicating the approximate location within the hypothalamus. In each image, the red box serves to orient the location of higher magnification images that follow. In the second row are two sets of three confocal photomicrographs of immunocytochemistry for the neuropeptide (red) and TUJ-1 (green) double-labeled (merged) cells detected in differentiated adult progenitor cultures of hippocampal (HI) and hypothalamic (HY) origins. AHA, Anterior hypothalamic area; AHNa, p, c anterior hypothalamic nucleus anterior, central, posterior parts; BSTif, $v$, bed nucleus stria terminalis posterior division interfasicular nucleus, anterior division ventral nucleus; $\mathrm{fx}$, columns of the fornix; LHA, lateral hypothalamic area; MPO, medial preoptic area; MPNm,I, medial preoptic nucleus medial, lateral parts; opt, optic tract; $\mathrm{PVpo}$, preoptic periventricular nucleus; $\mathrm{SCH}$, suprachiasmatic nucleus; S0, supraoptic nucleus; TU, tuberal area; $\mathrm{V} 3$, third ventricle.

positive neurons detected in our progenitor cultures are adult hypothalamic neuroendocrine cells that were simply harvested and retained their peptide phenotype after culture preparation. First, neuroendocrine neurons in the hypothalamus do not label with TUJ-1, because they are mature established neurons generated in embryo. Second, our density gradient centrifugation method eliminates virtually all differentiated neurons in the initial plating (Palmer et al., 1999). Third, adult neurons do not passage well, so that even if a single CRH-positive neuron were present in the initial plating, this neuron (which would, again, be TUJ-1 negative) would be unlikely to survive to passage one, let alone to passage four. Finally, Category II and III peptide-positive neurons were found in hippocampal cultures, and adult hippocampus does not contain cells of those phenotypes. In both hippocampal and hypothalamic cultures, immunopositive cells tended to be found in clusters. This impression was confirmed by field counts in which many fields contained no peptide-positive cells, and one field might contain 10 such cells (Fig. 3). Absorption with specific antigen eliminated positive immunocytochemical staining for the peptides examined, confirming the specificity of the antibodies used, and messenger RNA was detected for each peptide using PCR (Fig. 9).

In the hypothalamus proper, neuroendocrine neurons do not produce and store large quantities of peptide; rather, they produce and release these peptides as needed in an intricately and elegantly controlled manner. As a result, we had no expectation that we would find large quantities of peptide in cultured cells. To visualize neuroendocrine peptides in vivo, an intracerebroventricular injection of colchicine is used to halt the anterograde transport of peptides so that sufficient peptide remains in the soma for immunohistochemical detection. In anticipation of a minute peptide signal, we used a biotinylated tryamide secondary 


\section{Vasopressin}
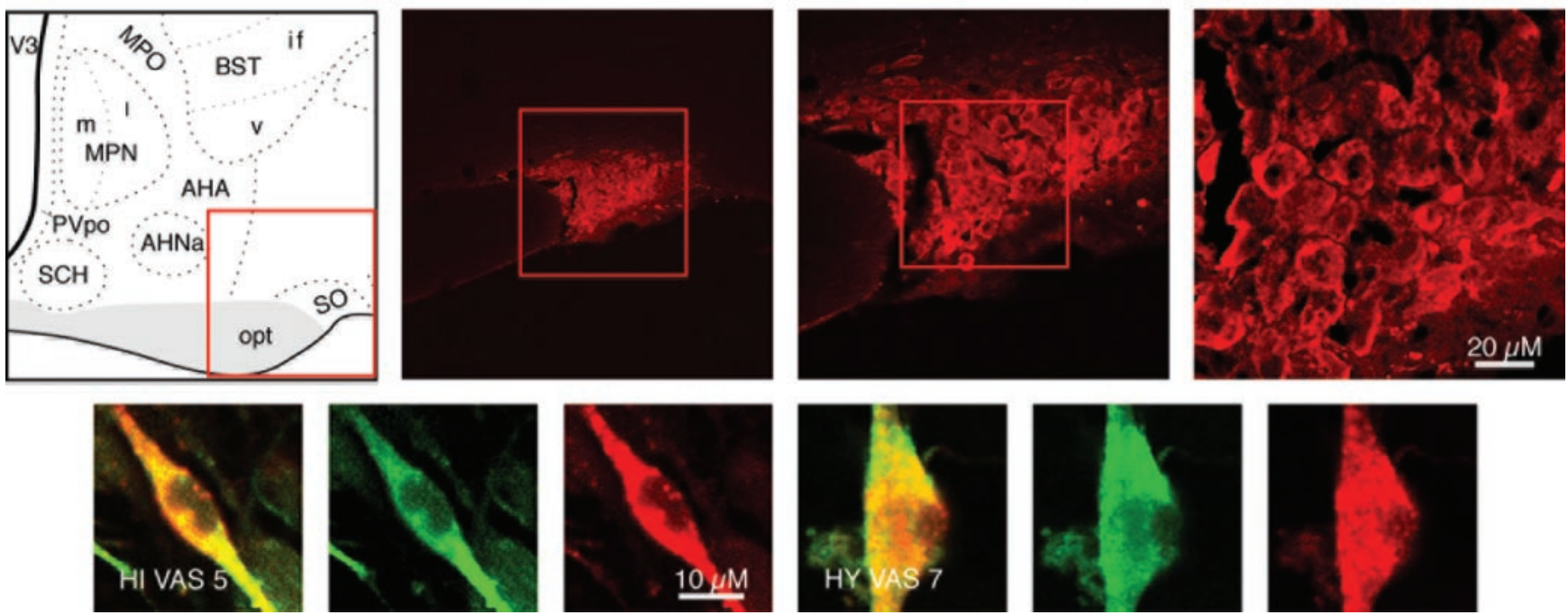

Figure 7. Category II neuropeptide VAS. Confocal photomicrographs in the top row are rat brain sections stained with the antibody to VAS. At left is an atlas graphic (Swanson, 1998) indicating the approximate location within the hypothalamus. In each image, the red box serves to orient the location of higher magnification images that follow. In the second row are two sets of three confocal photomicrographs of VAS (red) and TUJ-1 (green) double-labeled (merged) cells detected in differentiated adult progenitor cultures of hippocampal (HIVAS5) and hypothalamic (HYVAS7) origins. AHA, Anterior hypothalamic area; AHNa, anterior hypothalamic nucleus anterior part; BSTif,v, bed nucleus stria terminalis posterior division interfasicular nucleus, anterior division ventral nucleus; MPO, medial preoptic area; MPNm,l, medial preoptic nucleus medial part, lateral part; opt, optic tract; PVpo, preoptic periventricular nucleus; $\mathrm{SCH}$, suprachiasmatic nucleus; SO, supraoptic nucleus; $\mathrm{V} 3$, third ventricle.

\section{Gonadotropin-Releasing Hormone}
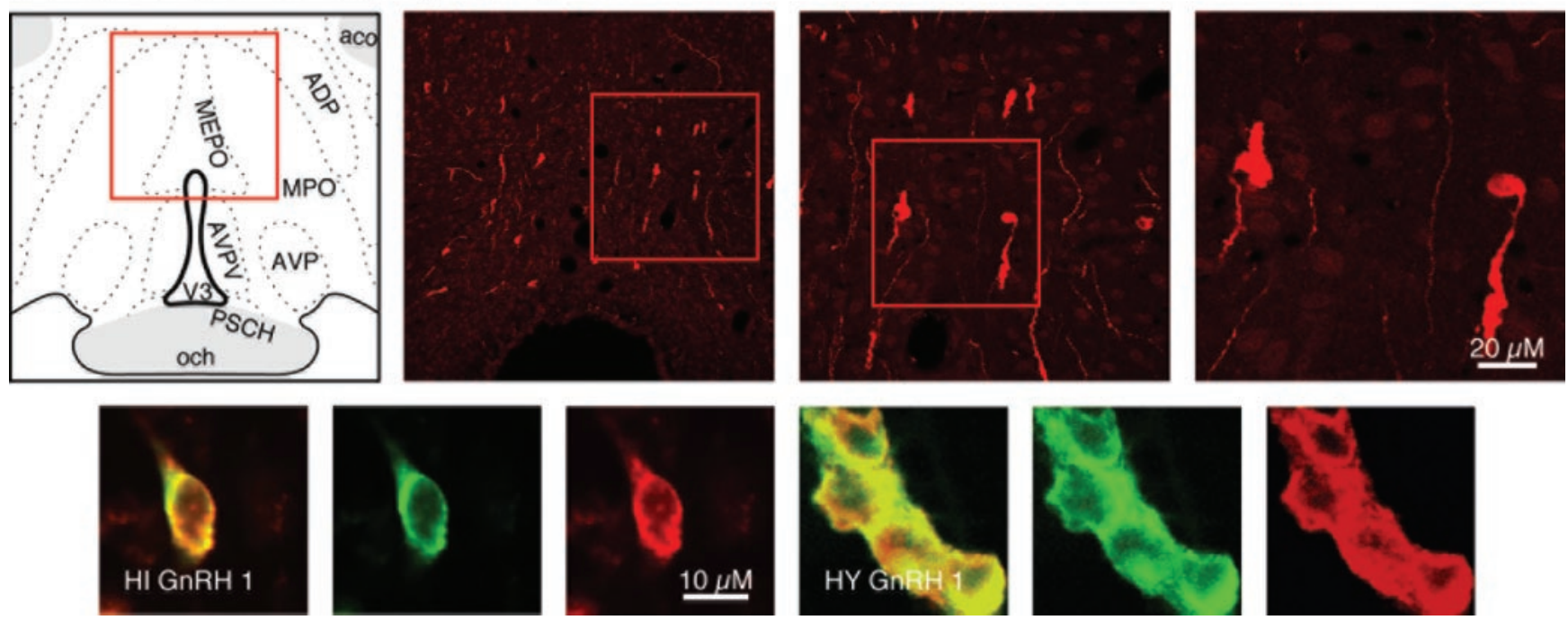

Figure 8. Category III neuropeptide GnRH. Confocal photomicrographs in the top row are rat brain sections stained with the antibody to GnRH. At left is an atlas graphic (Swanson, 1998) indicating the approximate location within the hypothalamus. In each image, the red box serves to orient the location of higher magnification images that follow. In the second row are two sets of three confocal photomicrographs of GnRH (red) and TUJ-1 (green) double-labeled (merged) cells detected in differentiated adult progenitor cultures of hippocampal (HIGnRH1) and hypothalamic (HYGnRH1) origins. aco, Anterior commissure olfactory limb; ADP, anterodorsal preoptic nucleus; AVP, anteroventral preoptic nucleus; AVPV, anteroventral periventricular nucleus hypothalamus; MEPO, median preoptic nucleus; MPO, medial preoptic area; och, optic chiasm; $\mathrm{PSCH}$, suprachiasmatic preoptic nucleus; V3p, third ventricle preoptic recess.

antibody amplification system to aid in the detection of neuroendocrine peptides in our cultures. Some peptides (GnRH, for example) were detectable without antibody amplification. To ensure that our immunodetection was appropriate, we sought confirmation for the detection of peptides. Nonquantitative RTPCR was used to confirm the presence of CRH and TRH. We performed PCR for CRH on undifferentiated hypothalamic cultures and PCR for TRH on both undifferentiated and differentiated hypothalamic cultures. CRH mRNA was detected in undifferentiated cultures (as predicted by the immunohistochemistry). TRH mRNA was detected in both differentiated (Fig. 9) and undifferentiated cultures, further confirming our immunocytochemical detection of peptides. Because of its greater sensitivity, we used Q-PCR and detected a message for all remaining peptides in both differentiated and undifferentiated progenitor cultures (Fig. 9).

\section{Discussion}

Our use of the word neuroendocrine in this work comes with the following caveat: neuroendocrine implies a function not a phenotype per se. In this work, neuroendocrine is used to refer to the 

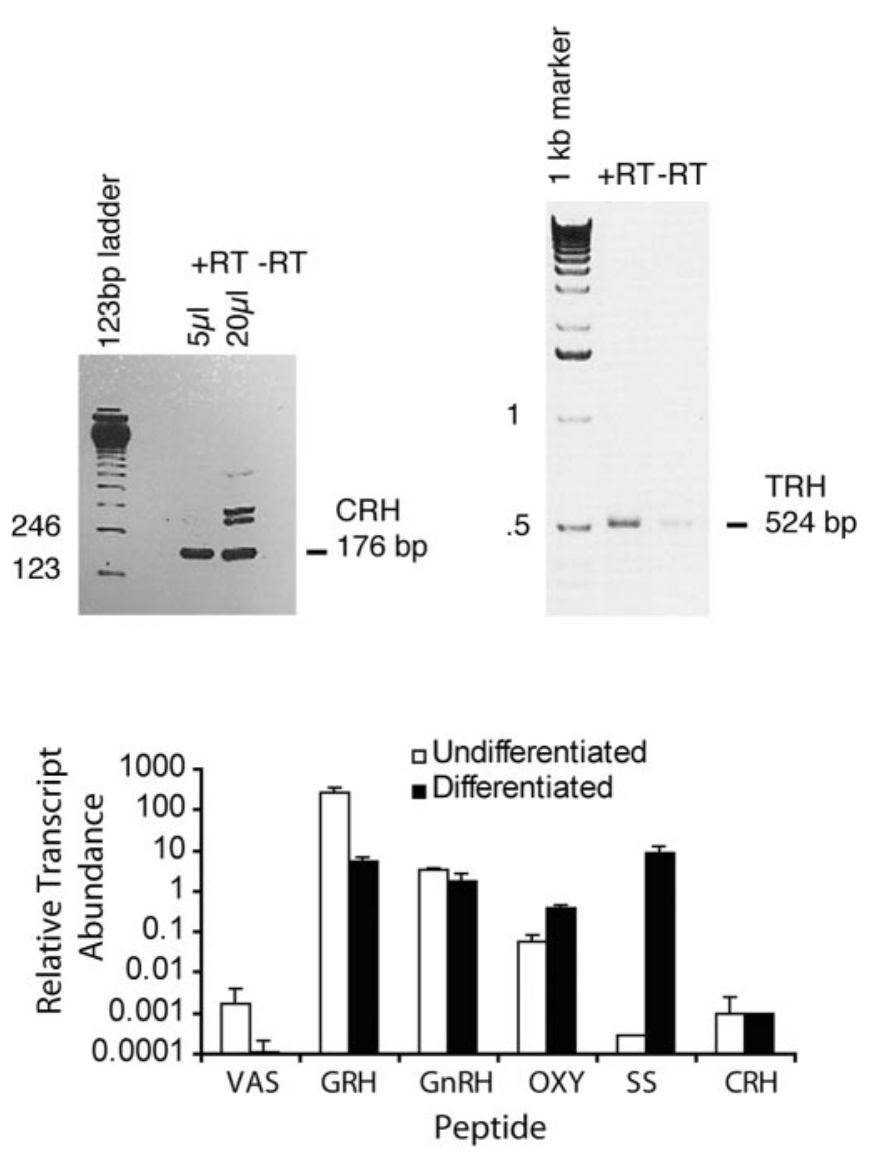

Figure 9. $P C R$. Nonquantitative RT-PCR gels confirm the presence of CRH mRNA in undifferentiated hypothalamic cultures and TRH mRNA in differentiated hypothalamic cultures. Q-PCR graph shows that the abundance of each peptide transcript was determined by quantitative PCR relative to a reference sample of RNA isolated from the intact rat neuraxis (brain and spinal cord). The reference sample contains authentic transcripts from all neuronal and glial cell types of the brain, including neurendocrine peptide transcripts. Although these data do not indicate absolute abundance of each transcript in the cultures, these do indicate that authentic transcripts for neural peptides exist within the culture at levels that fall within the linear detection range of the assay and within the range detected in normal rat brain tissues.

collection of known neuropeptide phenotypes of the cells that have this axonal projection and subserve this function. Furthermore, the progenitors that we recovered are from the brains of 7-week-old rats. Although their neuroarchitecture and neurochemisty are fully mature, these brains have a more active progenitor population than that of older adult rats whose proliferative population may be diminished or exhausted (Kuhn et al., 1996).

\section{Progenitor cells}

This work was designed to answer two questions in progenitor cell biology: (1) do quiescent progenitor cells, in the permissive environment of cell culture, have the potential to produce the same types of neurons as progenitors harvested from neurogenically active regions, and (2) is the type of neuron produced by a progenitor cell limited by the embryonic origin or adult location of that progenitor? These questions are aimed at teasing out the true nature of what it is to be a progenitor cell.

In vivo, adult progenitor cells in the dentate gyrus produce new neurons in the subgranule zone that migrate into the granule cell layer (Kuhn et al., 1996; Palmer et al., 2000) and send axonal projections to field $\mathrm{CA}_{3}$ and dendritic arbors into the molecular layer (Stanfield and Trice 1988; Markakis and Gage, 1999) to become integrated into the trisynaptic circuit. Progenitors in the subependymal zone give rise to immature cells that traverse the rostral migratory stream to become new neurons in the olfactory bulb (Luskin, 1993; Lois et al., 1996).

The hippocampus has been perhaps the best-studied source of neural progenitor cells; even so, the exact identity of the neural stem cell in the hippocampus is unknown, and there is some uncertainty regarding its location within the hippocampus. In their recent work, Seaberg and van der Kooy (2002) were unable to isolate stem cells from microdissection of the dentate gyrus, and they concluded that stem cells reside in the subependyma. However, they did not include the medial tip of the dentate gyrus in their dissection, the region with the highest density of proliferating cells. Rather, they contaminated their ventricular dissection with this dentate region. In previous studies (Palmer et al., 1999), we labeled adult brains with bromodeoxyuridine (BrdU) in vivo and created hippocampal progenitor cultures from these brains. In intact tissue sections, the BrdU labeling was concentrated in the subgranule zone of the dentate gyrus. Resultant cultures contained BrdU-labeled cells, were self-renewing, and produced both neuronal and glial cells, confirming that our progenitor culture methodology isolates the proliferative progenitor fraction from the dentate gyrus.

The hypothalamus contains progenitor cells, quiescent postnatally in vivo, that can be harvested, plated, and passaged over multiple population doublings. The neuronal offspring of these progenitors can produce all of the neuroendocrine neurotransmitters found in the hypothalamus in vivo. Ours is the first isolation of these hypothalamic progenitors, although we are not the first group to culture hypothalamic cells. Evans et al. (2002) cultured the hypothalamus and observed "mitotic neurons." We never observed mitosis in neurons; however, we isolated progenitor cells that can produce neurons in vitro.

The adult hippocampus continues to produce granule cells in vivo but can produce a wide array of different types of neurons in vitro, even those not found within the hippocampus. In contrast, the adult hypothalamus is neurogenically silent in vivo but contains quiescent progenitors that can proliferate in vitro. The phenotypes of the neurons generated by these cells were not dependent on the embryonic origin of the progenitors harvested, and clearly progenitor cells can generate classes of neurons not seen in their tissue of origin. How they generate neurons of such diverse phenotypes is unknown. This apparently indiscriminant differentiation has led us to believe that the neural precursors propagated in vitro are either influenced or selected by the culture conditions to display a much broader neuronal fate potential than is ever displayed in vivo. Our results indicate that there may be a default program for generating neurons, and that the details of phenotype determination are specified farther down the differentiation pathway. Such specification is absent in the permissive culture environment, and neurons of each peptide profile sought were detected, even neurons that produce GnRH.

\section{Development and proliferative zones}

Although there is no reason to expect adult neurogenesis to be a recapitulation of development, there are features of adult neurogenesis that suggest an important role for the ventricular zone. Indeed, after revisiting hippocampal development, one uncovers a ventricular surface hidden within the dentate gyrus (for review, see Alvarez-Bolado and Swanson, 1996.) In brief, the hippocampus develops as a ribbon of tissue in the embryo as viewed from above (supplemental Fig. 2; available at www.jneurosci.org), a 
continuation of the developing cortex that forms along the diencephalic and telencephalic roof plates. From medial to lateral, that ribbon of tissue is made up of the presumptive dentate gyrus, Ammon's horn, and strips of subicular and entorhinal cortex. A vast proliferation in Ammon's horn is followed by a similar proliferation in the dentate gyrus, which, situated medial-most, has no other place to expand. Thus, the dentate folds over onto itself as the ventricular space gets smaller, until there is no ventricle left, and the adult organization of the hippocampus emerges (in horizontal view, supplemental Fig. 2; available at www.jneurosci.org).

Most of the neurons that populate the hypothalamus are derived from the proliferative neuroepithelium of the third ventricle. The first wave of neurons generated occupies the lateral hypothalamus and, as development proceeds, the more medial and periventricular nuclei form, so that a lateral to medial gradient has been described (Ifft, 1972; van Eerdenburg and Rakic, 1994). This gradient is unique to the hypothalamus, and yet the observation that the proliferative cells of the neural tube mitose at the ventricular surface and then exhibit an interkinetic nuclear migration (Sauer, 1935; Sidman and Rakic, 1973) still holds. Thus, the proliferative heart of the ventral brain lies in the periventricular hypothalamus, the region chosen for the hypothalamic cultures in this work.

The neuroendocrine system is a rich environment for studying phenotype determination because of the numbers of phenotypically distinct neuronal populations with precise axonal projections that are generated in a relatively compact region. The parvicellular cells send an axonal projection to the median eminence and release their neurotransmitters into portal blood that washes over cells with the appropriate receptor types located in the adenohypophysis. Magnocellular neurons send their axonal projection to the neurohypophysis, where they release their peptides into the rich vasculature; there, they have their effect on peripheral targets with the appropriate receptors. Confoundingly, not all neuroendocrine peptide-producing cells send a projection to the neurohaemal zone (for review, see Markakis, 2002). In short, even within a single nucleus in the hypothalamus, not all $\mathrm{CRH}$ cells are created equal. However, they are all generated at the same time in development.

Studies of the development of neuroendocrine cells show that parvicellular neurons of each neurotransmitter phenotype are generated during the same time in embryo and that the parvicellular and magnocellular cells, producing distinctly different neurotransmitters and vastly divergent axonal projections, are being generated adjacent to each other in the same nucleus at the same time (Markakis and Swanson, 1997), along with a multitude of neurons that are not neuroendocrine in function. Those results suggest that there is a genetic component to neuroendocrine phenotype generation. In this work, it is apparent that this genetic program is accessible to stem cell progeny, regardless of embryonic origin. This plasticity is shown for the hippocampal progenitors by the generation of neurons of Category II and III and is apparent in the hypothalamic progenitor cells by the production of Category III neurons that produce GnRH. In embryo, these neurons are generated in the olfactory placode and migrate into the hypothalamus (Schwanzel-Fukuda and Pfaff, 1989; Wray et al., 1989). These placodally derived cells are not generated in situ, and yet hippocampal and hypothalamic progenitor cells generate neurons that make GnRH.

Embryogenesis is a story of proliferative zones. In the developing neural tube, proliferative neuroepithelia surround the ventricular zones. Thus, it makes sense that this natural repository for neurogenesis should be a source of progenitors in the adult brain. Indeed, there is some evidence that radial glia in the subependymal zone may be neural progenitors in the adult (Tramontin et al., 2003). The third ventricle does not maintain an environment in the adult brain that allows for ongoing neurogenesis, whereas the adult hippocampal formation and subependymal zone do.

In development in vivo, different subdivisons of the embryonic nervous system are populated by progenitors with regionand class-restricted potentials (Rakic, 1988; Rubenstein et al., 1994; Levitt et al., 1997; Fukuchi-Shimogori and Grove, 2001). However, the progenitors that persist in the postdevelopmental period seem to be truly multipotent, producing a wide variety of neurons in vitro with potential for use in clinical applications.

\section{References}

Alvarez-Bolado G, Swanson LW (1996) Developmental brain maps: struc ture of the embryonic rat brain. Amsterdam: Elsevier.

Alvarez-Buylla A (1990) Mechanism of neurogenesis in adult avian brain. Experientia 46:948-955.

Barry J, Dubois MP, Puolain P (1973) LRF producing cells of the mammalian hypothalamus. Z Zellforsch 146:351-366.

Bennett-Clarke C, Joseph SA (1982) Immunocytochemical distribution of LHRH neurons and processes in the rat: hypothalamic and extrahypothalamic locations. Cell Tissue Res 221:493-504.

Bloch B, Brazeau P, Ling N, Bohlen P, Esch F, Wherenberg WB, Benoit R, Bloom F, Guillemin R (1983) Immunohistochemical detection of growth hormone-releasing factor in brain. Nature 301:607-608.

Bloom FE, Battenberg ELF, Rivier J, Vale W (1982) Corticotropin releasing factor (CRF) immunoreactive neurons and fibers in the rat hypothalamus. Regul Pept 4:43-48.

Brownstein MJ, Eskay RL, Palkovits M (1982) Thyrotropin releasing hormone in the median eminence is in processes of paraventricular nucleus neurons. Neuropeptides 2:197-201.

Chan-Palay V, Zaborsky L, Kohler C, Goldstein M, Palay SL (1984) Distribution of tyrosine-hydroxylase-immunoreactive neurons in the hypothalamus of rats. J Comp Neurol 227:467-497.

Craig CG, Tropepe V, Morshead CM, Reynolds BA, Weiss S, van der Kooy D (1996) In vivo growth factor expansion of endogenous subependymal neural precursor cell populations in the adult mouse brain. J Neurosci 16:2649-2658.

Elde RP, Parsons JA (1975) Immunocytochemical localization of somatostatin in cell bodies of the rat hypothalamus. Am J Anat 144:541-548.

Eriksson PS, Perfilieva E, Bjork-Eriksson T, Alborn A, Nordborg C, Peterson DA, Gage FH (1998) Neurogenesis in the adult human hippocampus. Nat Med 4:1-5.

Evans J, Sumners C, Moore J, Huentelman MJ, Deng J, Gelband CH, Shaw G (2002) Characterization of mitotic neurons derived from adult rat hypothalamus and brain stem. J Neurophisiol 87:1076-1085.

Fukuchi-Shimogori T, Grove EA (2001) Neocortex patterning by the secreted signaling molecule FGF8. Science 294:1071-1074.

Gage FH (2002) Neurogenesis in the adult brain. J Neurosci 22:612-613.

Gage FH, Coates PW, Palmer TD, Kuhn HG, Fisher LJ, Suhonen JO, Peterson DA, Suhr ST, Ray J (1995) Survival and differentiation of adult neuronal progenitor cells transplanted to the adult brain. Proc Natl Acad Sci USA 92:11879-11883.

Gage FH, Kempermann G, Palmer TD, Peterson DA, Ray J (1998) Multipotent progenitor cells in the adult dentate gyrus. J Neurobiol 36:249-266.

Goldman SA, Nottebohm F (1983) Neuronal production, migration, and differentiation in a vocal control nucleus of the adult female canary brain. Proc Natl Acad Sci USA 80:2390-2394.

Gould E, Reeves AJ, Fallah M, Tanapat P, Gross CG, Fuchs E (1999) Hippocampal neurogenesis in adult Old World primates. Proc Natl Acad Sci USA 96:5263-5267.

Harzsch S, Dawirs RR (1996) Neurogenesis in the developing crab brain: postembryonic generation of neurons persists beyond metamorphosis. J Neurobiol 29:384-398.

Ibata Y, Watanabe K, Kinoshita H, Kubo S, Sanyo Y (1979) The location of LH-RH neurons in the rat hypothalamus and their pathways to the median eminence. Cell Tissue Res 198:381-395.

Ifft JD (1972) An autoradiographic study of the time of final division of neurons in rat hypothalamic nuclei. J Comp Neurol 144:193-204. 
Kirschenbaum B, Nedergaard M, Preuss A, Barami K, Fraser RA, Goldman SA (1994) In vitro neuronal production and differentiation by precursor cells derived from the adult human forebrain. Cereb Cortex 4:576-589.

Kondo T, Raff M (2000) Oligodendrocyte precursor cells reprogrammed to become multipotential CNS stem cells. Science 289:1754-1757.

Kornack DR, Rakic P (1999) Continuation of neurogenesis in the hippocampus of the adult macaque monkey. Proc Natl Acad Sci USA 96:5768-5773.

Kornack DR, Rakic P (2001) The generation, migration, and differentiation of olfactory neurons in the adult primate brain. Proc Natl Acad Sci USA 98:4752-4757.

Kuhn HG, Dickinson-Anson H, Gage FH (1996) Neurogenesis in the dentate gyrus of the adult rat: age-related decrease of neuronal progenitor proliferation. J Neurosci 16:2027-2033.

Lechan RM, Jackson IMD (1982) Immunohistochemical localization of thyrotropin releasing hormone (TRH) in the rat hypothalamus and pituitary. Endocrinol 111:55-61.

Levitt P, Barbe MF, Eagleson KL (1997) Patterning and specification of the cerebral cortex. Annu Rev Neurosci 20:1-24.

Lois C, Garcia-Verdugo JM, Alvarez-Buylla A (1996) Chain migration of neuronal precursors. Science 271:978-981.

Luskin MB (1993) Restricted proliferation and migration of postnatally generated neurons derived from the forebrain subventricular zone. Neuron 11:173-189.

Markakis EA (2002) Development of the neuroendocrine hypothalamus. Front Neuroendocrinol 23:257-291.

Markakis EA, Gage FH (1999) Adult-generated neurons in the dentate gyrus send axonal projections to field $\mathrm{CA}_{3}$ and are surrounded by synaptic vesicles. J Comp Neurol 406:449-460.

Markakis EA, Swanson LW (1997) Spatiotemporal patterns of secretomotor neuron generation in the parvicellular neuroendocrine system. Brain Res Brain Res Rev 24:255-291.

Menezes JR, Luskin MB (1994) Expression of neuron-specific tubulin defines a novel population in the proliferative layers of the developing telencephalon. J Neurosci 14:5399-5416.

Mullen RJ, Buck CR, Smith AM (1992) NeuN, a neuronal specific nuclear protein in vertebrates. Development 116:201-211.

Palmer TD, Ray J, Gage FH (1995) FGF-2-responsive neuronal progenitors reside in proliferative and quiescent regions of the adult rodent brain. Mol Cell Neurosci 6:474-486.

Palmer TD, Takahashi J, Gage FH (1997) The adult rat hippocampus contains primordial neural stem cells. Mol Cell Neurosci 8:389-404.

Palmer TD, Markakis EA, Willhoite AR, Safar F, Gage FH (1999) Fibroblast growth factor-2 activates a latent neurogenic program in neural stem cells from diverse regions of the adult CNS. J Neurosci 19:8487-8497.

Palmer TD, Willhoite AR, Gage FH (2000) Vascular niche for adult hippocampal neurogenesis. J Comp Neurol 425:479-494.

Parsons JA, Erlandsen SL, Hegr OD, McEvoy RC, Elde RP (1976) Central and peripheral localization of somatostatin immunocytochemical studies. J Histochem Cytochem 24:872-882.

Rakic P (1988) Specification of cerebral cortical areas. Science 241:170-176.

Rakic P (2002) Adult neurogenesis in mammals: an identity crisis. J Neurosci 22:614-618.

Reynolds BA, Tetzlaff W, Weiss S (1992) A multipotent EGF-reponsive striatal embryonic progenitor cell produces neurons and astrocytes. J Neurosci 12:4565-4574.

Rubenstein JL, Martinez S, Shimamura K, Puelles L (1994) The embryonic vertebrate forebrain: the prosomeric model. Science 266:578-580.
Sauer FC (1935) The cellular structure of the neural tube. J Comp Neurol 63:13-23.

Sawchenko PE (1987) Evidence for a differential regulation of corticotropinreleasing factor and vassopressin-immunoreactivities in parvocellular neurosecretory and autonomic-related projections of the paraventricular nucleus. Brain Res 437:253-263.

Sawchenko PE, Swanson LW, Rivier J, Vale WW (1985) The distribution of growth hormone-releasing factor (GRF) immunoreactivity in the central nervous system of the rat: an immunohistochemical study using antisera directed against rat hypothalamic GRF. J Comp Neurol 237:100-115.

Schwanzel-Fukuda M, Pfaff D (1989) Origin of leutenizing hormonereleasing hormone neurons. Nature 338:161-164.

Seaberg R, van der Kooy D (2002) Adult rodent neurogenic regions: the ventricular subependyma contains neural stem cells, but the dentate gyrus contains restricted progenitors. J Neurosci 22:1784-1793.

Sidman RL, Rakic P (1973) Neuronal migration with special reference to developing human brain: a review. Brain Res 62:1-35.

Simerly RB, Swanson LW (1987) The distribution of neurotransmitterspecific cells and fibers in the anteroventral periventricular nucleus: implications for the control of gonadotropin secretion in the rat. Brain Res 400:11-34.

Simerly RB, Gorski RZ, Swanson LW (1986) Neurotransmitter specificity of the cells and fibers in the medial preoptic nucleus: an immunohistochemical study in the rat. J Comp Neurol 246:343-363.

Stanfield BB, Trice JE (1988) Evidence that granule cells generated in the dentate gyrus of adult rats extend axonal projections. Exp Brain Res 72:399-406.

Swanson LW (1987) The hypothalamus. In: Handbook of chemical neuroanatomy, Vol 5 (Hokfelt T, Bjorklund A, Swanson LW, eds), pp 1-124. Amsterdam: Elsevier.

Swanson LW (1998) Brain maps: structure of the rat brain, Ed 2. Amsterdam: Elsevier.

Swanson LW, Sawchenko PE (1983) Hypothalamic integration: organization of the paraventricular and supraoptic nuclei. Annu Rev Neurosci 6:275-325.

Swanson LW, Sawchenko PE, Berod A, Hartman BK, Helle KB, VanOrden DE (1981) An immunohistochemical study of the organization of catecholaminergic cells and terminal fields in the paraventricular and supraoptic nuclei of the hypothalamus. J Comp Neurol 196:271-285.

Swanson LW, Sawchenko PE, Rivier J, Vale WW (1983) Organization of ovine corticotropin-releasing factor immunoreactive cells and fibers in the rat brain: an immunohistochemical study. Neuroendocrinology 36:165-186.

Tramontin AD, Garcia-Verdugo JM, Lim DA, Alvarez-Buylla A (2003) Postnatal development of radial glia and the ventricular zone (VZ): a continuum of the neural stem cell compartment. Cereb Cortex 13:580-587.

van Eerdenburg FJ, Rakic P (1994) Early neurogenesis in the anterior hypothalamus of the rhesus monkey. Brain Res Dev Brain Res 79:290-296.

Wessendorf MW, Appel NM, Molitor TW, Elde RP (1990) A method for immunofluorescent demonstration of three coexisting neurotransmitters in rat brain and spinal cord, using the fluorophores fluorescein, lissamine rhodamine, and 7-amino-4-methylcoumarin-3-acetic acid. J Histochem Cytochem 38:1859-1877.

Wray S, Grant P, Gainer H (1989) Evidence that cells expressing leutenizing hormone-releasing hormone mRNA in the mouse are derived from progenitor cells in the olfactory placode. Proc Natl Acad Sci USA 86:81328136. 